\title{
O SEBASTIANISMO SOB A ÓTICA OLIVEIRIANA
}

Wiliam Pianco ${ }^{1}$

RESUMO: Este artigo destina-se à análise de três filmes do cineasta Manoel de Oliveira: Non ou a vã glória de mandar (1990), Um filme falado (2003) e O quinto império - ontem como hoje (2004). O objetivo é compreender como tal realizador retoma o mito do Sebastianismo para questionar o posicionamento de Portugal no âmbito sociopolítico contemporâneo, nas escalas nacional, europeia e mundial. Assim, pretendemos refletir sobre a construção de um discurso que supomos ser historicamente alegórico.

PALAVRAS-CHAVE: Manoel de Oliveira; sebastianismo; Portugal; Alegoria histórica.

\begin{abstract}
This paper intends to analyze three movies by Manoel de Oliveira: Non ou a va glória de mandar (1990), Um filme falado (2003) and O quinto império - ontem como hoje (2004). The objective is to comprehend how this film maker retakes the Sebastianism's myth to question Portugal's position at contemporary social and political fields, in a national, european and worldwide scale. This way, we intend to think over the construction of a discourse that we suppose to be historically allegorical.
\end{abstract}

KEYWORDS: Manoel de Oliveira; sebastianism; Portugal; Historical allegory.

A hipótese que levantamos aqui é a de que Manoel de Oliveira lança mão de alegorias "explícitas" (XAVIER, 2005) para investigar um episódio histórico passado, visando, no entanto, refletir acerca de prolemáticas que se dão no presente e, assim, apontar expectativas para o futuro da nação portuguesa. Nesse panorama, sugerimos que, ao longo de seu discurso narrativo, o realizador esforça-se por estimular o desprendimento das amarras relacionadas ao sebastianismo, impulsionando, em contrapartida, uma atitude autônoma por parte de seus compatriotas naquilo que diz respeito à construção de seu próprio futuro.

Para tais pretensões, utilizaremos conceitos, além do de "alegoria histórica" (XAVIER, 2005), tais como as metodologias acerca do discurso da narrativa (GENETTE, 1972), do processo de criação do realizador (ARNHEIM, 1976) e do tripé "significante-signo-significado" a propósito das mitologias (BARTHES, 1993).

Começaremos com uma breve sinopse dos filmes mencionados:

Non ou a vã glória de mandar (1990): acompanha a viagem de um grupo de soldados portugueses em direção a alguma ex-colônia africana de Portugal, para que possam guerrear. A narrativa do filme se dá nos dias que antecedem a Revolução de 25 de abril de 1974, chamada de a Revolução dos Cravos e que determina o fim da ditadura salazarista/marcelista. Durante a viagem propriamente dita e nas paradas para descanso

\footnotetext{
${ }^{1}$ Mestre pelo PPGIS (Programa de Pós-Graduação em Imagem e Som), UFSCar (Universidade Federal de São Carlos).
} 
e alimentação, o Alferes (interpretado por Luis Miguel Cintra), líder do grupo de soldados, que é também professor de História, descreve episódios marcantes para Portugal. Sobretudo, passagens históricas que dizem respeito aos grandes feitos e às tentativas frustradas desse país em assumir o posto de Império mundial. Dentre os exemplos narrados pelo personagem estão as grandes navegações, com as Descobertas nos séculos XV e XVI, os esforços para uma União Ibérica plena e a Batalha de Alcácer-Quibir, que culmina na morte de D. Sebastião, em 1578, e inaugura o mito do sebastianismo português;

Um filme falado (2003): narra a viagem de navio realizada por mãe e filha portuguesas (Leonor Silveira e Felipa de Almeida, respectivamente) de Lisboa em direção a Bombaim, na Índia, onde devem encontrar com o pai da menina. Durante o trajeto, que se dá majoritariamente pelo Mar Mediterrâneo, Rosa Maria, que é professora de História, pode explicar à sua filha a relevância das cidades que vão conhecendo para a constituição das civilizações ocidentais e orientais. Outros personagens ganham importância à medida que a viagem ocorre: uma empresária francesa, uma ex-modelo italiana, uma atriz grega e o comandante norte-americano do navio.

O quinto império - ontem como hoje (2004): acompanha os momentos que antecedem a decisão tomada por D. Sebastião (interpretado por Ricardo Trêpa), em 1578, de invadir o Marrocos e, com isso, deflagrar a Batalha de Alcácer-Quibir. A narrativa do filme segue sempre em seu castelo, num clima claustrofóbico que parece sugerir a presença de uma mescla entre angústia e loucura, nos comportamentos de um rei obcecado pela glória futura. Após a derrota de Portugal nessa batalha, surge o mito do sebastianismo, que consiste na ideia de que um dia D. Sebastião retornará montado num cavalo branco para tirar Portugal do jugo de outras nações e conduzi-lo ao tão aguardado Quinto Império.

Após o descobrimento do continente americano, em meados do século XVI inúmeros aspectos da política adotada pelo governo português provocaram instabilidades no asseguramento de suas colônias, em seu crescimento econômico e na sua expansão marítima. Ao longo daquele século, o desenvolvimento e o posicionamento em âmbito mundial que Portugal havia alcançado e projetado encontravam-se ameaçados, assim, potências como Inglaterra e Holanda passaram a ameaçar os povos da Península Ibérica. 
Desta maneira, a união entre Portugal e, a hoje, Espanha passou a ser tema recorrente entre as suas lideranças.

Sob tal contexto é que nasce D. Sebastião, em 1554. Aos quatorze anos de idade, ele passa a tomar conta do governo e, desde então, suas grandes preocupações são sonhos de conquista e de expansão da fé cristã. Desta maneira é que a partir de 1574 começa a objetivar a invasão de Marrocos e a eliminação da prática da religião mulçumana de seu país. Somente em 1578 ele consegue formar um exército - consideravelmente fraco e em mau estado de disciplina e organização. Exército este apoiado por mercenários alemães, espanhóis e italianos. Nesse episódio, que decorre nos campos de AlcácerQuibir, as tropas portuguesas (e aliadas) foram completamente derrotadas. O que ficou marcado como "a batalha mais desastrosa da história portuguesa" (MARQUES, 1998). D. Sebastião foi morto e com ele a nata da aristocracia e do exército de seu país.

Assim, deu-se origem ao mito de D. Sebastião. Ou seja, a crença de que ele não havia morrido em Alcácer-Quibir e que voltaria em breve para reclamar o trono que lhe pertencia. Parecia a todos monstruosa a derrota e morte do jovem monarca, com então 24 anos de idade. Sobretudo, porque isso implicaria a dependência portuguesa frente à Espanha - situação que duraria de 1580 a 1640.

A partir das profecias de um tal sapateiro de nome Bandarra, que anunciara a vinda de um rei encoberto, redentor da humanidade, acreditavam que D. Sebastião viria numa manhã de nevoeiro para salvar a nação e devolvê-la à independência. Por sua vez, judeus e cristãos-novos, conhecedores da Bíblia e do seu messianismo hebraico, passaram a associar o sebastianismo com a crença no próximo Quinto Império bíblico.

O sebastianismo assumira, assim, duas funções principais: 1) como sinônimo daquilo que contrariava a União Ibérica; 2) a esperança de que um dia virá, enfim, um Salvador da Pátria. A primeira se consolidou; a segunda, ainda hoje, seria aguardada!

Propomos que o conjunto de filmes aqui analisado pode ser pensado a partir do conceito de "alegoria histórica" (XAVIER, 2005), na medida em que se constitui como um discurso cuja enunciação nem sempre aponta para significados evidentes, aparentes, trabalhando em contrapartida com sentidos ocultos, disfarçados e enigmáticos. O discurso de Manoel de Oliveira pressupõe, dessa forma, uma certa cadeia polissêmica ambígua, a qual, contudo, remete para o questionamento da nação portuguesa no âmbito de um contexto globalizado, em que as alegorias elaboradas indicam um pensamento crítico sobre a contemporaneidade, compreendida em perspectiva histórica. Ou seja, seu 
discurso implica um impulso de memória de um momento anterior da história que acaba por comunicar um sentimento de crise devido à presença (decaída) do passado no presente. Trata-se, portanto, de alegorias

nas quais as analogias implícitas entre o passado e o presente são tomadas como uma estratégia retórica, uma forma de fazer uma pergunta sobre o presente utilizando o passado, em função da semelhança entre as questões atuais e aquelas enfocadas no filme (XAVIER, 2005, p. 369-370).

Para tanto, designa aos seus personagens uma tarefa essencial: sustentar seu discurso, que, em última análise, tem a pretensão de promover uma reflexão crítica que passa pela percepção do papel exercido por Portugal no âmbito sociopolítico globalizado.

Tais hipóteses encontram pertinência a partir da observação das argumentações de Roland Barthes, em seu Mitologias (1993).

Como vimos, D. Sebastião morre em 1578, na batalha de Alcácer-Quibir, originando o mito do sebastianismo. Mas também resulta na dependência de Portugal para com a Espanha (1580 - 1640) e numa série de consequências políticas e econômicas que têm seus resultados imediatos, como a perda de inúmeros portos mercantis em África, Índia e China; e em resultados futuros, como a quase falência do Estado nos séculos que seguem. Situação tal que, de certa maneira, encontra ecos na Revolução dos Cravos em 1974, na complicada entrada de Portugal na então Comunidade Econômica Europeia, em 1986, e no seu papel na contemporaneidade - seja na União Europeia ou mesmo na CPLP - Comunidade dos Países de Língua Portuguesa.

Em seu famoso contributo à semiologia, Barthes afirma que “(...) o mito é um sistema de comunicação, é uma mensagem. Eis por que não poderia ser um objeto, um conceito, ou uma ideia: ele é um modo de significação, uma forma”. Então, “já que o mito é uma fala, tudo pode constituir um mito, desde que seja suscetível de ser julgado por um discurso" (BARTHES, 1993, p. 131).

Outra passagem pertinente:

(...) pode conceber-se que haja mitos muito antigos, mas não eternos; pois é a história que transforma o real em discurso, é ela e só ela que comanda a vida e a morte da linguagem mítica. Longínqua ou não, a mitologia só pode ter um fundamento histórico, visto que o mito é uma fala escolhida pela história: não poderia de modo algum surgir da "natureza" das coisas (ibidem).

Portanto, para os nossos interesses neste trabalho, três aspectos se destacam nas colocações de Barthes: o mito enquanto discurso, enquanto fala histórica e como elemento não natural, livre da natureza. 
Diz o autor:

Recordo portanto que toda a semiologia postula uma relação entre dois termos, um significante e um significado. Relacionando objetos de ordem diferente, não constitui uma igualdade, mas sim uma equivalência. É preciso não esquecer que, contrariamente ao que se sucede na linguagem comum, que me diz simplesmente que o significante exprime o significado, devem-se considerar em todo o sistema semiológico não apenas dois, mas três termos diferentes; pois o que se apreende não é absolutamente um termo, um após o outro, mas a correlação que os une: temos portanto o significante, o significado e o signo, que é o total associativo dos dois primeiros termos (BARTHES, 1993, p. 134-135).

Sucede que o sistema mítico utiliza o signo (desse sistema tridimensional significante, significado e signo), e o transforma em um novo significante. Assim, origina uma nova cadeia de relações, com um novo significado e um novo signo.

Ou seja, na pretensão de transformar um episódio histórico em natural, o mito desloca o eixo de suas definições. Sendo assim, poderíamos arriscar dizer que o que se arrasta nas lembranças portuguesas já não é a morte de D. Sebastião e todas as suas consequências históricas, mas sim a esperança de que um salvador venha tirá-los de uma suposta "apatia", atrelada a determinado senso de "não-inscrição", tal como nos sugere José Gil (2004).

Parece-nos que é sobre essa linha reflexiva que Manoel de Oliveira vai construir suas representações, expressões, críticas e discurso com relação ao mito do sebastianismo. Desta maneira é que, em 1990, dezesseis anos após a Revolução dos Cravos, ele vai filmar Non ou a vã glória de mandar - sua primeira crítica explícita ao referido mito. Nesse filme, conforme pudemos observar, o Alferes relata diversos episódios de Portugal ao longo da História a fim de consolidar-se como grande Império.

A relação mais imediata se dá ao término, quando do falecimento do Alferes. Isso porque ele morre em 25 de abril de 1974, ou seja, na data da Revolução que tira Marcelo Caetano (sucessor de Salazar) do poder.

Pensamos que, ao dar tal desfecho ao que seria a consciência histórica de Portugal no filme (figura alegórica do Alferes), Manoel de Oliveira está sugerindo que o sebastianismo já não é mais necessário à sua nação. Em outras palavras, o 25 de abril seria um marco representativo para a exclusão de um suposto Salvador da Pátria. Esse não mais seria necessário, já que o povo conduziria, com suas próprias forças, seu futuro dali por diante. Da mesma maneira, a morte do Alferes é importante no sentido de determinar um novo início, ou um novo episódio, para a história dessa nação. Aqui é 
importante lembrarmos que a Revolução tinha duas grandes metas: 1) acabar com a ditadura e implantar a democracia; 2) acabar com as colonizações em África.

Já em Um filme falado, de 2003, Manoel de Oliveira constroi uma alegoria acerca do papel de Portugal no contexto contemporâneo. Sendo assim, devemos cruzar suas abordagens com a entrada complicada da nação portuguesa no bloco econômico dos países europeus, em 1986. Nessa obra, suas reflexões vão ao encontro do papel ocupado hoje pela língua portuguesa em âmbito mundial e para a situação periférica em que se encontra Portugal, quando contrastado com as demais nações desse continente.

Por este motivo, o filme aborda duas vertentes: a primeira diz respeito às civilizações que contribuíram para a consolidação do mundo ocidental; a segunda, para as relações multinacionais em âmbito globalizado - representadas alegoricamente por um navio que comporta diversas nações e é conduzido por um comandante estadunidense sem nome. Imediatamente ao mito de D. Sebastião, é interessante notarmos que ele não é merecedor, pelo menos no filme, de um monumento, quadro, placa ou escultura de devoção. Enquanto outros nomes portugueses (D. Henrique, Vasco da Gama), ou mesmo de outras nacionalidades (Athena, os faraós), têm figurações concretas em sua homenagem, D. Sebastião é lembrado apenas em decorrência de um nevoeiro.

A partir disso, é significativo destacarmos o ponto de partida da jornada decorrida no filme. Ou seja, ao se comprometer com a travessia de milênios de civilização, Oliveira opta por partir, justamente, dos feitos gloriosos de Portugal com os Descobrimentos, passando pela Batalha de Alcácer-Quibir e a Revolução dos Cravos estabelecendo uma dinâmica discursiva e alegórica sustentada por essa tríade. Assim, as primeiras referências históricas atribuídas apresentam-se da seguinte maneira: o Padrão dos Descobrimentos, o mito de D. Sebastião, a Revolução dos Cravos e, aí sim, o passado mais longínquo. Por exemplo, na primeira sequência, quando pretende mostrar à filha o Monumento aos Descobrimentos, Rosa Maria diz: “Está a vir um nevoeiro. É pena. Se aumentar, não conseguirá ver o monumento aos Descobrimentos"; e pouco depois: "Engraçado, este denso nevoeiro faz-me lembrar do mito de D. Sebastião", ao que a menina questiona: “O que é um mito?”, e ela responde: “Chama-se mito, histórias imaginadas a partir de certos acontecimentos".

É interessante notarmos estas passagens do filme sob a perspectiva que parece sugerir as construções alegóricas. Dessa maneira, pensando na tríade composta pelas referências aos Descobrimentos, à Batalha de Alcácer-Quibir e à Revolução dos Cravos, o mito do sebastianismo poderia encobrir a visão de Maria Joana (a filha) para os 
episódios anteriores a ele - mais dignos para Oliveira, e destacados através das falas de Rosa Maria. Há, portanto, em todo o discurso da mãe, uma preocupação em relatar o que é fato histórico, distinguindo-o de interpretações equivocadas acerca dos mesmos eventos. Poderíamos mesmo dizer que há, por parte daquela, adequando-se ao entendimento possível da menina, a responsabilidade de esclarecer a difusa dinâmica significante-significado-signo, tal como nos sugere Barthes (1993). Por estes motivos, defendemos a extensão do discurso oliveiriano que, como comentamos, surge com Non ou a vã glória de mandar, mas que parece ir além neste Um filme falado.

Por fim, O quinto império - ontem como hoje (2004) é a declaração crucial do lamento que Manoel de Oliveira parece cultivar por D. Sebastião. A narrativa do filme segue sempre no castelo daquele rei português, num clima claustrofóbico que parece sugerir a presença de uma mescla entre angústia e loucura, nos comportamentos de um líder obcecado pela glória futura. O filme parece querer finalizar sua opinião acerca do tema. Se é possível que Non ou a vã glória de mandar verse diretamente com a Revolução de 1974, no que diz respeito ao fim do sebastianismo, e que Um filme falado já o trate como uma questão ultrapassada, $O$ quinto império não deixa dúvidas ou trabalha com sutilezas ao abordar o tema. Aqui, efetivamente, é estabelecida a desmitificação do antigo rei. Explorando ao máximo a tetralidade em sua forma cinematográfica, Manoel de Oliveira cria um ambiente hermético em que a busca por uma justificativa acerca dos desatinos do jovem monarca ganha um contorno praticamente terapêutico.

Nesse filme, Oliveira adapta a peça de teatro El-Rei Sebastião (José Régio, 1949) regressando à fidelidade ao texto escrito após um longo intervalo em que tal cinematografia fora caracterizada por adaptações, relativamente, livres por parte do cineasta (sobretudo com os títulos produzidos ao longo da década de 1990). Apesar da referida fidelidade ao texto de Régio, a alteração do título sublinha nitidamente a continuação e a atualidade deste imaginário para a contemporaneidade. De acordo com Carolin Overhoff Ferreira (2008b), o filme faz parte de um grupo de seis filmes sobre as políticas de expansão portuguesas e europeias, nos quais a perspectiva de um Quinto Império, advinda da profecia de Padre António Vieira é sempre referida em menor ou maior grau. A autora sugere que o corpus de filmes dedicado a essa temática, além do título de 2004, inicia-se com O sapato de cetim (1985), passando por Non ou a vã glória de mandar (1990), Palavra e utopia (2000), Um filme falado (2003) e Cristovão Colombo - o enigma (2007). 
A partir de $O$ quinto império - ontem como hoje, suspeitamos que sua interpretação alegórica indica o tempo contemporâneo, no qual o conflito entre as culturas cristã e islâmica atinge proporções extremas e globais. Nele, Oliveira critica e mostra as razões irracionais (perpetuação de um passado glorioso, desejo de prestígio eterno, sonhos de grandeza que vão além da realidade econômica de um país) que levam o Ocidente a invadir países com outras crenças.

Ao nosso entender, a questão do mito de D. Sebastião estaria mais ou menos como a personagem Touro está para Guernica, de Picasso. Ou seja, como elemento agregador, como ponto essencial para onde remetem-se os olhares que buscam em seu conjunto de filmes a perspectiva de um painel. Painel esse, no caso, discursivo. E, assim, pretendemos refletir e suscitar a reflexão sobre esse personagem do quadro maior da obra cinematográfica de Oliveira.

Referindo-nos ao projeto do diretor, gostaríamos de finalizar este pensamento com uma citação de Cecília Almeida Salles, em seu Gesto inacabado (1998), obra relevante para os estudos dos processos de criação: "Cada obra é uma possível concretização do grande projeto que direciona o artista. Se a questão da continuidade for levada às últimas consequências, pode-se ver cada obra como um rascunho ou concretização parcial desse grande projeto" (SALLES, 1998, p. 39). Em outras palavras, o sebastianismo serviria, portanto, como agente essencial para um conjunto de filmes desse realizador: iniciado com Non ou a vã glória de mandar e a sua crítica associada à Revolução de abril de 1974; chegando a Um filme falado, com seu esforço em distinguir fato de mito; finalizando com $O$ quinto império - ontem como hoje e a sua crítica definitiva. Assim é que a opinião de Oliveira sobre o mito de D. Sebastião parece-nos expressada. 


\section{Referências bibliográficas:}

ARNHEIM, Rudolf. Génesis de una pintura: El "Guernica" de Picasso. Trad. Esteve Riambau i Saurí. Espanha: Colección Comunicación Visual, 1976.

AUERBACH, Erich. Figura. Trad. Duda Machado. São Paulo: Editora Ática, 1997.

BAECQUE, Antoine de; PARSI, Jacques. Conversas com Manoel de Oliveira. Trad. Henrique Cunha. Porto: Campo das Letras - Editores S.A., 1999.

BARTHES, Roland. Mitologias. $9^{\circ}$ Edição. Trad. Léa Novaes. Rio de Janeiro: Editora Bertrand Brasil,1993.

CARONE, Modesto. "Um roteiro do conceito de figura". In: Erich Auerbach. Figura. Trad. Duda Machado. São Paulo: Editora Ática, 1997.

COSTA, João Bénard da. Histórias do cinema. Lisboa: Imprensa Nacional-Casa da Moeda, 1991.

FERREIRA, Carolin Overhoff (coord.). O cinema português através dos seus filmes. Porto: Campo das Letras - Editores S.A., 2007.

FERREIRA, Carolin Overhoff (ed.). Dekalog 2 - On Manoel de Oliveira. London: Wallflower Press, 2008a.

FERREIRA, C. O. "Palavra sem utopia: a adaptação de El-Rei Sebastião por Manoel de Oliveira". In.: RECORTE - Revista de Linguagem, Cultura e Discurso. Ano 5, Número 9, Julho a dezembro de 2008b.

GENETTE, Gérard. Discurso da narrativa. Trad. Fernando Cabral Martins. Lisboa: Vega Ltda., 1972.

GIL, José. Portugal, hoje - O medo de existir. $5^{\circ}$ ed. Lisboa: Relógio D’Água, 2004.

MACHADO, Álvaro (org.). Manoel de Oliveira. São Paulo: Cosac \& Naify, 2005.

MARQUES, A. H. de Oliveira. Breve história de Portugal. Lisboa: Presença, 1998.

SALLES, Cecília Almeida. Gesto Inacabado: Processo de Criação Artística. São Paulo: Annablume 1998.

SHOHAT, Ella; STAM, Robert. Crítica da imagem eurocêntrica: multiculturalismo e representação. São Paulo: Cosac \& Naify, 2006.

XAVIER, Ismail. "A alegoria histórica". In: Fernão Ramos. Teoria contemporânea do cinema, vol. 1. São Paulo: SENAC, 2005. 